\title{
Influence of delivery characteristics and socioeconomic status on giving birth by caesarean section - a cross sectional study during 2000-2010 in Finland
}

Sari Räisänen ${ }^{1,2^{*}}$, Mika Gissler ${ }^{3,4}$, Michael R Kramer ${ }^{1}$ and Seppo Heinonen ${ }^{2,5}$

\begin{abstract}
Background: Caesarean section (CS) rates especially without medical indication are rising worldwide. Most of indications for CS are relative and CS rates for various indications vary widely. There is an increasing tendency to perform CSs without medical indication on maternal request. Women with higher socioeconomic status (SES) are more likely to give birth by CS. We aimed to study whether giving birth by CS was associated with SES and other characteristics among singleton births during 2000-2010 in Finland with publicly funded health care.

Methods: Data were gathered from the Finnish Medical Birth Register. The likelihood of giving birth by CS according to CS type (planned and non-planned), parity (nulliparous vs. multiparous), socio-demographic factors, delivery characteristics and time periods (2000-2003, 2004-2007 and 2008-2010) was determined by using logistic regression analysis. SES was classified as upper white collar workers (highest SES), lower white collar workers, blue collar workers (lowest SES), others (all unclassifiable cases) and cases with missing information.

Results: In total, $19.8 \%(51,511$ of 259,736$)$ of the nulliparous women and $13.1 \%(47,271$ of 360,727$)$ of the multiparous women gave birth by CS. CS was associated with several delivery characteristics, such as placental abruption, placenta previa, birth weight and fear of childbirth, among both parity groups. After adjustment, the likelihood of giving birth by planned CS was reduced by $40 \%$ in nulliparous and $55 \%$ in multiparous women from 2000-2003 to 2008-2010, whereas the likelihood of non-planned CSs did not change. Giving birth by planned and non-planned CS was up to $9 \%$ higher in nulliparous women and up to $17 \%$ higher in multiparous women in the lowest SES groups compared to the highest SES group.

Conclusions: Giving birth by CS varied by clinical indications. Women with the lowest SES were more likely to give birth by CS, indicating that the known social disparity in pregnancy complications increases the need for operative deliveries in these women. Overall, the CS policy in Finland shows favoring a trial of labor over planned CS and reflects no inequity in healthcare services.
\end{abstract}

Keywords: Birth, Caesarean section, Childbirth, Population register, Register, Socioeconomic status

\footnotetext{
* Correspondence: shraisan@student.uef.fi

'Department of Epidemiology, Rollins School of Public Health, Emory

University, 1518 Clifton Road NE, Atlanta, GA, USA

2Department of Obstetrics and Gynaecology, Kuopio University Hospital,

P.O. Box 100, Kys, Kuopio, Fl 70029, Finland

Full list of author information is available at the end of the article
} 


\section{Background}

Caesarean section (CS) rates vary substantially between countries, especially between low-income and high-income countries, indicating a great disparity in the availability of this life-saving obstetric procedure across the world [1-3]. The World Health Organization (WHO) has recommended an optimal CS rate of $15 \%$ based on the CS rates of countries with the lowest maternal and neonatal mortality rates [4]. CS rates have been constantly rising in many developed countries, such as the European countries [5], especially due to the increasing tendency to perform CSs without medical indication on maternal request [6,7]. In 2010, among the European countries, CS rates varied from $52.2 \%$ in Cyprus to $14.8 \%$ in Iceland. Only The Netherlands, Slovenia, Finland, Sweden, Iceland, and Norway had CS rates below 20\% [5]. However, CS rates in Europe did not correlate with national wealth, as measured by the gross domestic product (http://epp.eurostat. ec.europa.eu/statistics_explained/index.php/GDP_per_ capita,_consumption_per_capita_and_price_level_indices). The major indications for CS are repeated caesarean section, dystocia, breech presentation, foetal conditions (such as macrosomia, prematurity, anomalies or abnormal lie), foetal distress, multiple pregnancies and maternal conditions (such as antepartum haemorrhage, diabetes and preeclampsia) [8]. However, most of the indications are relative and CS rates for various indications vary widely [8]. Previous population based studies from Australia, Canada and UK reported higher prevalence of CS performed due to repeated CS [9-11], dystocia [11] and elective prelabor CS, especially for nulliparous women [12]. A few previous studies have demonstrated differences in CS rates between socioeconomic status (SES) groups within countries. Women with low SES or living in deprived areas were less likely to give birth by CS compared to women with high SES or living in affluent areas $[13,14]$, even in countries with publicly funded healthcare $[15,16]$, indicating that inequity may exist in some healthcare services. On the other hand, a large population based study from the Norway reported that women with the lowest level of education were more likely to give birth by CS [17].

In Finland, previous studies have reported SES disparities in amenable deaths [18] and invasive cardiac procedures $[19,20]$, showing that women with the highest SES have the lowest risk. Further, women with the highest SES were more likely to undergo in vitro fertilization in Finland [21-23]. In Finland, practically all pregnant women give birth in public hospitals with free-access, and private delivery care services are not provided. The aim of the present study was to explore whether giving birth by planned and non-planned CS was associated with SES and other characteristics among singleton pregnancies during 2000-2010 in Finland.

\section{Methods}

\section{Data and population}

The study population included all women with singleton births $(N=620,463)$ during 2000-2010 in Finland; multiple births $(n=19,305)$ were excluded. Data were gathered retrospectively from the Finnish Medical Birth Register (MBR) and included information on socio-demographic, pregnancy and delivery characteristics, and diagnoses on all live births or stillbirths (after the 22nd gestational week or weighing $500 \mathrm{~g}$ or more) during the first seven days after birth. Information on maternal diseases and reproductive risk factors, such as preeclampsia, diabetes mellitus, gestational diabetes, placental abruption, depression and fear of childbirth, was gathered based on the International Classification of Diseases (ICD-10) codes contained in the Hospital Discharge Register (HDR) and linked with the MBR data by using parturients' encrypted personal identification numbers. Both national health registers (established in 1987 and 1967, respectively) are currently maintained by the National Institute for Health and Welfare (THL).

\section{Variables and definitions}

Women were classified into two groups based on the number of prior childbirths: nulliparous (no prior childbirths) and multiparous women (one or more prior childbirths). Mode of delivery was defined either as vaginal birth, including spontaneous vaginal, breech, instrumental (forceps or vacuum assisted) or CS (planned or non-planned). Maternal age was classified as less than 20, 20-29, 30-39 and 40 years or more (advanced age). Birth weight was classified as less than 3000, 3000-3499, 3500-3999 and 4000 grams or more. Women were also grouped based on self-reported smoking habits during pregnancy: non-smoking, quitted smoking during the first trimester or continued smoking after the first trimester, i.e., smoking and missing information. Marital status was classified as either married (including unmarried women living with a partner) or single.

SES was categorized based on Finland's National Classification of Occupations [24], which follows international recommendations. SES was categorized based on maternal occupation at birth, yielding five groups: upper white-collar workers, such as physicians and lawyers; lower white-collar workers, such as nurses and secretaries; blue-collar workers, such as cooks and cleaners; others; and missing information, as categorized and published elsewhere [25]. 'Others' included all cases with unclassifiable occupations, such as entrepreneurs, students, retired, unemployed and housewives. The category with missing information on SES comprised $17 \%(n=105,472)$ of all cases.

Information on preeclampsia, diabetes mellitus, gestational diabetes, placental abruption and fear of childbirth was defined according to ICD-10 codes gathered from 
the HDR. Information on prior miscarriages and terminations was dichotomous (yes or no). In vitro fertilization (IVF) included intracytoplasmic sperm injection (ICSI) and frozen embryo transfers (FET). Body mass index (BMI) gathered since 2004 was calculated by dividing body weight in kilograms by the squared height in meters $\left(\mathrm{kg} / \mathrm{m}^{2}\right)$. The study period was divided into three time periods (2000-2003, 2004-2007 and 2008-2010) to evaluate secular trends.

\section{Ethical approval}

Permission to use the confidential register data in this study was granted on 16th February, 2012 by the THL in Finland. THL also approved the study (Reference number 1749/5.05.00/2011).

\section{Statistical analyses}

Bivariable analyses were performed separately for nulliparous and multiparous women with different prevalence of CS $(p \leq 0.001)$. Differences between the groups (nulliparous and multiparous women giving birth with and without CS, any type) were evaluated by chi square test for dichotomous and categorical variables, and Student's $t$-test for continuous variables.

To test whether there were differences in the prevalence of CS births (separately for planned and non-planned) between SES groups and other characteristics, we performed unconditional logistic regression analysis (backward elimination), using women with vaginal birth as a reference group in both parity groups. Possible confounders (maternal age, birth weight, foetal sex, smoking status, marital status, SES, induction, preeclampsia, gestational diabetes, maternal diabetes mellitus, fear of childbirth, placental abruption, placenta previa, IVF, prior terminations, prior miscarriages, prior $\mathrm{CS}$ and time period) were selected based on bi-variable analyses $(p<0.1)$. In addition, we studied the contribution of demographics and delivery characteristics on the odds ratio (OR) of SES for CS births (separately for planned and non-planned) according to parity (nulliparous and multiparous women), using women with vaginal birth as a reference group. Each variable was added separately to Model 2 (adjusted by maternal age), prior CS birth (in multiparous women) (Model 3), birth weight (Model 4), smoking (Model 5), and the full model (Model 6, adjusted by age, prior CS births, birth weight and smoking). OR with 95\% confidence intervals (CI) were calculated. The contribution of smoking to CS associated with SES was measured based on the percentage reduction in the OR of SES by using the formula (OR Model 2 - OR Model 5)/ (OR Model 2 - 1). To avoid bias arising from missing information on SES, we performed further analyses by using multiple imputations. Differences were deemed to be significant if the $p$-value was less than 0.05 . The data were analyzed using SPSS for Windows 19.0, Chicago, IL.

\section{Results}

In total, $19.8 \%(51,511$ of 259,736$)$ of the nulliparous women and $13.1 \%(47,271$ of 360,727$)$ of the multiparous women with singleton births gave birth by CS during 2000-2010 in Finland (Table 1). The total CS rate was relatively constant during the 11 -year study period among both parity groups. Women who gave birth by CS were in general older, gave birth more frequently to a male infant with lower mean gestational age and were more likely to have high SES (upper or lower white collar worker) than women who gave birth vaginally, regardless of parity. As expected, giving birth by $\mathrm{CS}$ was associated with several reproductive risk factors during index pregnancy, such as induction, preeclampsia, gestational diabetes, diabetes mellitus, IVF, placental abruption, placenta previa and fear of childbirth, as well as prior history of pregnancy terminations and miscarriages among both parity groups. Nulliparous women with infants weighing less than 3000 grams or at least 4000 grams and multiparous women with infants weighing less than 3000 grams were more likely to undergo CS. Multiparous women were more likely to give birth by CS if they had a prior history of CS birth.

After adjustment for case-mix in logistic regression analysis, the prevalence of planned CS births in nulliparous women was 9\% (adjusted odds ratio (aOR) 1.09, 95\% confidence interval (CI) 1.03-1.11) higher in lower white collar workers, and the prevalence of non-planned CS birth was 7\% (aOR 1.07, 95\% CI 1.01-1.13) higher in blue collar workers compared to upper white collar workers (Table 2). In multiparous women, the prevalence of planned CS was 17\% (aOR 1.17, 95\% CI 1.11-1.24) higher in lower white collar workers and 16\% (aOR 1.16, 95\% CI 1.09-1.24) higher in blue collar workers compared to upper white collar workers (Table 2), whereas the prevalence of nonplanned CS was 15\% (aOR 1.15, 95\% CI 1.07-1.23) higher in blue collar workers compared to upper white collar workers. Differences between other SES groups were nonsignificant regardless of parity and CS type.

Placenta previa was the strongest risk factor for planned $\mathrm{CS}$ and placental abruption was the strongest risk factor for non-planned CS, regardless of parity. Other delivery characteristics associated with planned CS birth were advanced maternal age ( $\geq 40$ years), a birth weight of less than 3000 grams, a birth weight of 4000 grams or more, maternal diabetes mellitus, fear of childbirth and IVF, regardless of parity. Delivery characteristics associated with non-planned CS birth were advanced maternal age, a birth weight of less than 3000 grams, a birth weight of 4000 grams or more, preeclampsia, gestational diabetes, fear of childbirth, IVF and prior terminations, regardless of parity. Further, in nulliparous women, an increased prevalence of non-planned CS birth was associated with 
Table 1 Demographics and delivery characteristics among singleton births according to caesarean section (CS) and parity during 2000-2010 in Finland

\begin{tabular}{|c|c|c|c|c|c|c|}
\hline \multirow[t]{2}{*}{ Characteristic } & \multicolumn{2}{|c|}{ Nulliparous, $n=259,736$} & \multirow[t]{2}{*}{$p$ value ${ }^{*}$} & \multicolumn{2}{|c|}{ Multiparous, $n=360,727$} & \multirow[t]{2}{*}{$p$ value* } \\
\hline & $\begin{array}{c}\mathrm{CS}, n=51,511 \\
(19.8 \%)\end{array}$ & $\begin{array}{c}\text { Vaginal birth, } \\
n=208,225\end{array}$ & & $\begin{array}{c}\mathrm{CS}, n=47,271 \\
(13.1 \%)\end{array}$ & $\begin{array}{c}\text { Vaginal birth, } \\
n=313,456\end{array}$ & \\
\hline Planned CS, $n$ (\% of CSs) & $15,420(29.9)$ & NA & & $26,987(57.1)$ & NA & \\
\hline Non-planned CS, $n$ (\% of CSs) & $36,091(70.1)$ & NA & & $20,284(42.9)$ & NA & \\
\hline Mean number of prior births (SD) & NA & NA & & $1.7(1.3)$ & $1.8(1.5)$ & $\leq 0.001$ \\
\hline Mean maternal age, years (SD) & $29.0(5.5)$ & $27.0(5.1)$ & $\leq 0.001$ & $32.4(5.1)$ & $30.8(5.0)$ & $\leq 0.001$ \\
\hline Maternal age, years \% & & & $\leq 0.001$ & & & $\leq 0.001$ \\
\hline$<20$ & 3.5 & 6.6 & & 0.2 & 0.4 & \\
\hline $20-29$ & 51.6 & 63.4 & & 28.8 & 40.5 & \\
\hline $30-39$ & 41.4 & 28.8 & & 62.8 & 54.6 & \\
\hline 40 or more & 3.5 & 1.2 & & 8.2 & 4.5 & \\
\hline Mean gestational age, weeks (SD) & $39.4(2.4)$ & $39.9(1.7)$ & $\leq 0.001$ & $38.8(2.3)$ & $39.9(1.6)$ & $\leq 0.001$ \\
\hline Mean birth weight, g (SD) & $3398(710)$ & $3439(500)$ & $\leq 0.001$ & $3492(720)$ & $3524(509)$ & $\leq 0.001$ \\
\hline Birth weight, g\% & & & $\leq 0.001$ & & & $\leq 0.001$ \\
\hline$<3000$ & 22.3 & 16.0 & & 18.1 & 9.1 & \\
\hline 3000-3499 & 29.8 & 37.9 & & 28.2 & 29.1 & \\
\hline 3500-3999 & 30.0 & 34.4 & & 31.6 & 39.7 & \\
\hline 4000 or more & 17.9 & 11.7 & & 22.1 & 22.1 & \\
\hline Male fetal sex \% & 53.8 & 50.6 & $\leq 0.001$ & 52.4 & 51.0 & $\leq 0.001$ \\
\hline Smoking status \% & & & $\leq 0.001$ & & & $\leq 0.001$ \\
\hline Non-smoking & 80.9 & 80.3 & & 82.8 & 84.2 & \\
\hline Quit smoking during 1st trimester & 5.0 & 5.2 & & 2.5 & 2.3 & \\
\hline Smoking after 1 st trimester & 11.7 & 12.6 & & 11.0 & 10.6 & \\
\hline Missing information & 2.4 & 2.0 & & 3.7 & 2.9 & \\
\hline Married or living with a partner \% & 91.3 & 90.5 & $\leq 0.001$ & 95.0 & 95.2 & 0.07 \\
\hline Socioeconomic status \% & & & $\leq 0.001$ & & & $\leq 0.001$ \\
\hline Upper white-collar workers & 8.9 & 7.8 & & 8.8 & 8.5 & \\
\hline Lower white-collar workers & 34.2 & 31.3 & & 38.6 & 36.3 & \\
\hline Blue-collar workers & 13.9 & 13.7 & & 15.5 & 15.0 & \\
\hline Others $^{\mathrm{a}}$ & 24.2 & 27.7 & & 21.7 & 25.0 & \\
\hline Missing information & 18.8 & 19.5 & & 15.4 & 15.2 & \\
\hline Mean body mass index (SD) & $24.8(5.0)$ & $23.5(4.3)$ & $\leq 0.001$ & $25.9(5.5)$ & $24.4(4.7)$ & $\leq 0.001$ \\
\hline Induction \% & 19.1 & 16.2 & $\leq 0.001$ & 9.1 & 17.1 & $\leq 0.001$ \\
\hline Preeclampsia \% & 3.3 & 0.3 & $\leq 0.001$ & 4.3 & 1.1 & $\leq 0.001$ \\
\hline Gestational diabetes \% & 11.3 & 6.7 & $\leq 0.001$ & 19.7 & 12.1 & $\leq 0.001$ \\
\hline Maternal diabetes mellitus \% & 9.1 & 4.7 & $\leq 0.001$ & 15.7 & 8.9 & $\leq 0.001$ \\
\hline In vitro fertilization (IVF) \% & 3.4 & 1.9 & $\leq 0.001$ & 1.5 & 0.7 & $\leq 0.001$ \\
\hline Placental abruption \% & 83.5 & 16.5 & $\leq 0.001$ & 78.0 & 22.0 & $\leq 0.001$ \\
\hline Placenta previa \% & 78.2 & 21.8 & $\leq 0.001$ & 81.4 & 18.6 & $\leq 0.001$ \\
\hline Fear of childbirth \% & 6.5 & 2.0 & $\leq 0.001$ & 15.3 & 4.1 & $\leq 0.001$ \\
\hline Prior terminations \% & 12.3 & 11.1 & $\leq 0.001$ & 14.9 & 13.3 & $\leq 0.001$ \\
\hline Prior miscarriages \% & 15.2 & 12.2 & $\leq 0.001$ & 29.3 & 26.0 & $\leq 0.001$ \\
\hline
\end{tabular}




\begin{tabular}{|c|c|c|c|c|c|c|}
\hline Prior caesarean section \% & NA & NA & & 64.3 & 11.1 & $\leq 0.001$ \\
\hline Time period \% & & & 0.18 & & & $\leq 0.001$ \\
\hline 2000-2003 & 19.7 & 80.3 & & 13.3 & 86.7 & \\
\hline 2004-2007 & 19.8 & 80.2 & & 13.2 & 86.8 & \\
\hline 2008-2010 & 20.0 & 80.0 & & 12.7 & 87.3 & \\
\hline
\end{tabular}

${ }^{a}$ Others comprised entrepreneurs, students, retired women, unemployed women, housewives and all unclassifiable cases.

${ }^{*}$ Chi-square or Student's $t$-test, SD = standard deviation, NA = not applicable.

smoking and induction of labor. In multiparous women, prior CS birth was associated with an increased risk of both CS types.

After adjustment for case-mix, the prevalence of planned CS appeared to decrease by $40 \%$ in nulliparous women and by $55 \%$ in multiparous women from 20002003 to 2008-2010, whereas differences in non-planned CSs between the time periods were non-significant. The same logistic regression analyses were performed for both groups of women using multiple imputations for the missing data, but the results did not change (data not shown).

Table 3 presents crude and adjusted ORs of SES for CS birth (separately for planned and non-planned CSs) according to parity and different confounders. Delivery characteristics were added separately to Model 2 (adjusted for maternal age) to evaluate the contribution of each characteristic to the ORs of SES for CS birth. It appeared that maternal age made a major contribution and maternal smoking during pregnancy a moderate contribution to the prevalence of both CS types associated with SES. Further, the contribution made by the birth weight was minor. In nulliparous women, $21.4 \%$ of the differences in planned CS birth prevalence and $17.4 \%$ of the differences in non-planned CS birth prevalence between blue collar workers and upper white collar workers could be explained by smoking during pregnancy (percentage reduction in OR of SES-CS between Model 2 and Model 5 in Table 3). In multiparous women, $18.8 \%$ and $19.2 \%$ of the difference between blue collar workers and upper white collar workers in planned and nonplanned CS births, respectively, could be explained by smoking during pregnancy.

\section{Discussion}

\section{Statement of principal findings}

During the study period of 2000-2010 in Finland, the total CS rate in nulliparous women was $19.8 \%$ and $13.1 \%$ in multiparous women. Giving birth by CS varied by clinical indications reflecting equity in delivery care services. Giving birth by CS (planned or non-planned) was 7-9\% more common in nulliparous women with lower SES compared to upper white collar workers (highest
SES). Giving birth by CS (planned or non-planned) was $15-17 \%$ more common in multiparous women with lower SES compared to upper white collar workers. Maternal age made a major contribution to the variation in CS births between the SES groups, whereas the contribution of smoking during pregnancy was moderate. After adjustment for background factors, giving birth by planned CS reduced by $40 \%$ in nulliparous women and by $55 \%$ in multiparous women from 2000-2003 to 2008-2010, whereas differences in giving birth by non-planned CS were nonsignificant. These figures indicate that as a policy, trial of labor has been favored over planned CS.

\section{Strengths and weaknesses}

The present study has several strengths. First, the data, covering the total population of women with singleton births during recent years, were gathered from two national health registers containing high quality data. Second, we were able to use a variety of characteristics as confounders in the analyses, and performed analyses separately for nulliparous and multiparous women with significantly different prevalence of CS. The most important limitation was that information on SES was missing in $17 \%$ of the cases. Information on SES is optional and an increasing number of women do not wish to provide this type of sensitive information. Based on our previous analyses and characteristics, we suggest that women with missing SES represented all SES categories. To reduce the bias caused by missing information on SES, we performed multiple imputations, but this did not change the results. Further, SES was solely based on maternal occupation at birth and we did not have information on education and household income. However, in Finland, these are known to correlate with occupation, which is therefore an appropriate indicator for studies on socioeconomic health disparity [26,27]. Further, we did not have information on spouses' SES because of data protection issues. Another limitation was that the MBR does not include the actual diagnosis of CS with ICD-10 codes CS. Further, a proportion of the planned CSs performed out of office hours might have been classified as non-planned CS births. 
Table 2 Adjusted odds ratios (aORs) of planned and non-planned caesarean section (CS) births according to parity during 2000-2010 in Finland, using women with vaginal birth as a reference group in all analyses (logistic regression analysis)

\begin{tabular}{|c|c|c|c|c|}
\hline \multirow[t]{3}{*}{ Characteristic } & \multicolumn{2}{|c|}{ Nulliparous women } & \multicolumn{2}{|c|}{ Multiparous women } \\
\hline & $\begin{array}{c}\text { Planned CS, } \\
n=14,514\end{array}$ & $\begin{array}{c}\text { Non-planned CS, } \\
n=33,873\end{array}$ & $\begin{array}{c}\text { Planned CS, } \\
n=26,132\end{array}$ & $\begin{array}{c}\text { Non-planned CS, } \\
\quad n=19,555\end{array}$ \\
\hline & aOR $(95 \% \mathrm{Cl})$ & aOR $(95 \% \mathrm{Cl})$ & aOR $(95 \% \mathrm{Cl})$ & aOR $(95 \% \mathrm{Cl})$ \\
\hline \multicolumn{5}{|l|}{ Maternal age (years) } \\
\hline$<20$ & 1 & 1 & 1 & 1 \\
\hline $20-29$ & $1.35(1.23-1.49)$ & $1.56(1.46-1.67)$ & $1.34(0.97-1.85)$ & $1.08(0.81-1.44)$ \\
\hline 30-39 & $2.39(2.17-2.64)$ & $2.54(2.37-2.72)$ & $1.94(1.40-2.69)$ & $1.37(1.03-1.83)$ \\
\hline 40 or more & $4.85(4.23-5.55)$ & $4.14(3.75-4.58)$ & $2.74(1.97-3.81)$ & $1.83(1.36-2.46)$ \\
\hline \multicolumn{5}{|l|}{ Birth weight (g) } \\
\hline$<3000$ & $1.56(1.48-1.64)$ & $1.69(1.64-1.75)$ & $1.49(1.42-1.57)$ & $3.49(3.33-3.65)$ \\
\hline 3000-3499 & $1.20(1.15-1.26)$ & 1 & $1.30(1.26-1.35)$ & $1.09(1.05-1.14)$ \\
\hline 3500-3999 & 1 & $1.27(1.23-1.31)$ & 1 & 1 \\
\hline 4000 or more & $1.47(1.39-1.56)$ & $2.24(2.16-2.33)$ & $1.13(1.06-1.21)$ & $1.46(1.40-1.52)$ \\
\hline Male fetal sex & $0.94(0.91-0.98)$ & $1.20(1.67-1.22)$ & $1.04(1.01-1.07)$ & $1.20(1.17-1.24)$ \\
\hline \multicolumn{5}{|l|}{ Smoking status } \\
\hline Non-smoking & 1 & 1 & 1 & 1 \\
\hline Quit smoking during 1st trimester & $1.06(0.98-1.13)$ & $1.07(1.01-1.13)$ & $1.07(0.97-1.18)$ & $1.18(1.07-1.31)$ \\
\hline Smoking after 1 st trimester & $0.94(0.89-1.00)$ & $1.10(1.06-1.15)$ & $1.01(0.96-1.06)$ & $1.00(0.95-1.06)$ \\
\hline Missing information & $1.36(1.21-1.52)$ & $1.15(1.06-1.25)$ & $1.41(1.30-1.53)$ & $1.17(1.07-1.28)$ \\
\hline Single (ref married/living with a partner) & $0.93(0.87-0.99)$ & $0.99(0.95-1.03)$ & $1.02(0.95-1.10)$ & $1.12(1.04-1.20)$ \\
\hline \multicolumn{5}{|l|}{ Socioeconomic status } \\
\hline Upper white collar workers & 1 & 1 & 1 & 1 \\
\hline Lower white collar workers & $1.09(1.02-1.16)$ & $1.05(1.00-1.10)$ & $1.17(1.11-1.24)$ & $1.07(1.00-1.11)$ \\
\hline Blue collar workers & $1.03(0.95-1.11)$ & $1.07(1.01-1.13)$ & $1.16(1.09-1.24)$ & $1.15(1.07-1.23)$ \\
\hline Others $^{a}$ & $0.95(0.89-1.02)$ & $0.93(0.88-0.97)$ & $0.98(0.92-1.04)$ & $0.92(0.87-0.98)$ \\
\hline Missing information & $0.96(0.89-1.03)$ & $1.01(0.96-1.06)$ & $1.13(1.06-1.21)$ & $1.08(1.01-1.15)$ \\
\hline Induction & NA & $1.64(1.59-1.68)$ & NA & $0.97(0.94-1.01)$ \\
\hline Preeclampsia & $6.41(5.53-7.44)$ & $11.77(10.62-13.04)$ & $1.04(0.96-1.14)$ & $2.12(1.95-2.30)$ \\
\hline Gestational diabetes & $0.55(0.49-0.62)$ & $1.34(1.26-1.43)$ & $1.07(1.01-1.15)$ & $1.39(1.30-1.48)$ \\
\hline Maternal diabetes mellitus & $3.95(3.51-4.46)$ & $1.14(1.06-1.23)$ & $1.66(1.54-1.78)$ & $1.06(0.98-1.15)$ \\
\hline Fear of childbirth & $7.99(7.53-8.48)$ & $1.58(1.48-1.70)$ & $5.05(4.83-5.28)$ & $1.67(1.58-1.78)$ \\
\hline Placental abruption & NA & $29.42(24.22-35.74)$ & NA & $61.78(52.87-72.20)$ \\
\hline Placenta previa & $25.35(20.56-31.25)$ & $8.05(6.46-10.04)$ & 39.65 (32.73-48.04) & $22.41(18.46-27.20)$ \\
\hline In vitro fertilization (IVF) & $1.25(1.13-1.38)$ & $1.25(1.16-1.34)$ & $1.49(1.30-1.72)$ & $1.86(1.63-2.12)$ \\
\hline Prior terminations & $1.02(0.97-1.08)$ & $1.09(1.05-1.13)$ & $1.10(1.05-1.15)$ & $1.10(1.05-1.15)$ \\
\hline Prior miscarriages & $1.16(1.10-1.22)$ & $1.12(1.08-1.16)$ & $0.99(0.96-1.03)$ & $1.00(0.96-1.03)$ \\
\hline Prior caesarean section & NA & NA & $20.60(19.97-21.24)$ & $8.32(8.06-8.60)$ \\
\hline \multicolumn{5}{|l|}{ Time period } \\
\hline 2000-2003 & $1.40(1.34-1.47)$ & $0.94(0.92-0.97)$ & $1.55(1.49-1.61)$ & $\begin{array}{c}1.02 \\
(0.98-1.06)\end{array}$ \\
\hline 2004-2007 & $1.21(1.16-1.27)$ & $0.95(0.92-0.98)$ & $1.22(1.18-1.27)$ & $1.03(0.99-1.07)$ \\
\hline 2008-2010 & 1 & 1 & 1 & 1 \\
\hline
\end{tabular}


Table 3 Odds ratios (ORs) of planned and non-planned caesarean section (CS) births associated with socioeconomic status (SES) after adjustment for delivery characteristics according to parity during 2000-2010 in Finland

\begin{tabular}{|c|c|c|c|c|c|c|}
\hline \multirow[b]{3}{*}{ Planned CS } & \multirow[t]{2}{*}{ Model 1 crude } & \multirow{2}{*}{$\begin{array}{l}\text { Model } 2 \\
\text { Adjusted by } \\
\text { maternal age }\end{array}$} & \multirow{2}{*}{$\begin{array}{l}\text { Model } 3 \\
\text { Adjusted by Model } 2+ \\
\text { prior } \mathrm{CS}^{\mathrm{a}}\end{array}$} & \multirow{2}{*}{$\begin{array}{l}\text { Model } 4 \\
\text { Adjusted by Model } 2+ \\
\text { birth weight }\end{array}$} & \multirow{2}{*}{$\begin{array}{l}\text { Model } 5 \\
\text { Adjusted by Model } 2+ \\
\text { smoking }\end{array}$} & \multirow{2}{*}{$\begin{array}{l}\text { Model } 6 \\
\text { Adjusted by Model 2+ prior } \mathrm{CS}^{\mathrm{a}} \text {, } \\
\text { birth weight and smoking }\end{array}$} \\
\hline & & & & & & \\
\hline & OR $(95 \% \mathrm{Cl})$ & OR $(95 \% \mathrm{Cl})$ & OR $(95 \% \mathrm{Cl})$ & OR $(95 \% \mathrm{Cl})$ & OR $(95 \% \mathrm{Cl})$ & OR $(95 \% \mathrm{Cl})$ \\
\hline \multicolumn{7}{|l|}{ Nulliparous women } \\
\hline \multicolumn{7}{|l|}{ SES } \\
\hline Upper white collar workers & 1 & 1 & NA & 1 & 1 & 1 \\
\hline Lower white collar workers & $0.93(0.87-0.98)$ & $1.13(1.07-1.21)$ & & $1.13(1.06-1.20)$ & $1.13(1.06-1.20)$ & $1.12(1.05-1.19)$ \\
\hline Blue collar workers & $0.79(0.74-0.85)$ & $1.14(1.06-1.22)$ & & $1.13(1.05-1.21)$ & $1.11(1.03-1.20)$ & $1.11(1.03-1.19)$ \\
\hline Others $^{b}$ & $0.74(0.70-0.80)$ & $1.04(0.97-1.11)$ & & $1.04(0.97-1.10)$ & $1.03(0.97-1.10)$ & $1.03(0.97-1.10)$ \\
\hline Missing information & $0.76(0.71-0.81)$ & $1.01(0.95-1.08)$ & & $1.00(0.94-1.07)$ & $1.00(0.93-1.07)$ & $0.99(0.93-1.06)$ \\
\hline \multicolumn{7}{|l|}{ Multiparous women } \\
\hline \multicolumn{7}{|l|}{ SES } \\
\hline Upper white collar workers & 1 & 1 & 1 & 1 & 1 & 1 \\
\hline Lower white collar workers & $1.03(0.98-1.08)$ & $1.15(1.10-1.21)$ & $1.17(1.11-1.24)$ & $1.15(1.10-1.20)$ & $1.14(1.09-1.20)$ & $1.16(1.10-1.22)$ \\
\hline Blue collar workers & $0.96(0.91-1.01)$ & $1.16(1.10-1.22)$ & $1.18(1.11-1.25)$ & $1.14(1.08-1.21)$ & $1.13(1.07-1.19)$ & $1.14(1.08-1.22)$ \\
\hline Others $^{b}$ & $0.83(0.79-0.88)$ & $1.00(0.95-1.05)$ & $1.02(0.96-1.07)$ & $0.99(0.94-1.04)$ & $0.99(0.94-1.04)$ & $1.00(0.95-1.06)$ \\
\hline Missing information & $0.95(0.90-1.00)$ & $1.12(1.06-1.18)$ & $1.16(1.09-1.23)$ & $1.11(1.05-1.17)$ & $1.10(1.05-1.17)$ & $1.14(1.07-1.21)$ \\
\hline Non-planned CS & OR $(95 \% \mathrm{Cl})$ & OR $(95 \% \mathrm{Cl})$ & OR $(95 \% \mathrm{Cl})$ & OR $(95 \% \mathrm{Cl})$ & OR $(95 \% \mathrm{Cl})$ & OR $(95 \% \mathrm{Cl})$ \\
\hline \multicolumn{7}{|l|}{ Nulliparous women } \\
\hline \multicolumn{7}{|l|}{ SES } \\
\hline Upper white collar workers & 1 & 1 & NA & 1 & 1 & 1 \\
\hline Lower white collar workers & $0.96(0.92-1.00)$ & $1.13(1.08-1.18)$ & & $1.13(1.08-1.18)$ & $1.12(1.07-1.17)$ & $1.12(1.07-1.17)$ \\
\hline Blue collar workers & $0.92(0.87-0.96)$ & $1.23(1.17-1.29)$ & & $1.22(1.16-1.29)$ & $1.19(1.13-1.25)$ & $1.19(1.13-1.25)$ \\
\hline Others $^{b}$ & $0.77(0.73-0.80)$ & $1.01(0.97-1.06)$ & & $1.01(0.96-1.05)$ & $1.00(0.96-1.05)$ & $1.00(0.96-1.05)$ \\
\hline Missing information & $0.87(0.83-0.91)$ & $1.10(1.05-1.15)$ & & $1.10(1.05-1.15)$ & $1.09(1.03-1.14)$ & $1.08(1.03-1.13)$ \\
\hline \multicolumn{7}{|l|}{ Multiparous women } \\
\hline \multicolumn{7}{|l|}{ SES } \\
\hline Upper white collar workers & 1 & 1 & 1 & 1 & 1 & 1 \\
\hline Lower white collar workers & $1.04(0.99-1.10)$ & $1.14(1.08-1.20)$ & $1.15(1.09-1.22)$ & $1.12(1.06-1.18)$ & $1.12(1.06-1.19)$ & $1.12(1.06-1.19)$ \\
\hline Blue collar workers & $1.09(1.02-1.15)$ & $1.26(1.18-1.33)$ & $1.29(1.21-1.37)$ & $1.20(1.13-1.27)$ & $1.21(1.14-1.29)$ & $1.22(1.14-1.30)$ \\
\hline Others $^{b}$ & $0.87(0.82-0.92)$ & $1.00(0.94-1.06)$ & $1.01(0.96-1.08)$ & $0.97(0.91-1.03)$ & $0.98(0.93-1.04)$ & $0.98(0.92-1.04)$ \\
\hline Missing information & $1.04(0.98-1.10)$ & $1.18(1.11-1.25)$ & $1.20(1.12-1.28)$ & $1.12(1.06-1.19)$ & $1.16(1.09-1.23)$ & $1.14(1.06-1.21)$ \\
\hline
\end{tabular}

NA $=$ not applicable, ${ }^{a}$ Prior CS birth adjusted only in multiparous women.

bothers comprised entrepreneurs, students, retired women, unemployed women, housewives and all unclassifiable cases. 


\section{Meaning and implications of the study}

In the present study, we found that giving birth by CS was strongly associated with delivery characteristics such as birth weight and reproductive risk factors such as advanced maternal age, placental abruption and placenta previa in a country with exclusively publicly funded delivery care services. Further, we found up to 9 and 17\% higher prevalence of CS births (any type) in women with lower SES (lower white collar workers and blue collar workers) compared to women with the highest SES (upper white collar workers) for nulliparous and multiparous women, respectively. This finding was in accordance with a previous study that reported a parallel but constantly increasing SES disparity during 1967-2004 in Norway, which has a similar kind of welfare system to Finland [17]. In the present study, the SES disparity was smaller among nulliparous women than multiparous women. It might be speculated that the increased prevalence of CS births in the nulliparous women with lower SES compared to the highest SES might result in an increased SES disparity in subsequent births due to prior CS birth, which is a strong risk factor for CS in subsequent births, as reported by previous studies [28,29]. That might in part explain the constantly rising prevalence of CS births among women with the lowest education reported by a Norwegian study [17].

The higher prevalence of CS births among the women with lowest compared to highest SES might partially be explained by an increased risk of adverse outcomes, such as preterm birth and small for gestational age (SGA), as shown previously in Finland using the same data [30,31], particularly as adverse health behavior such as smoking is known to be strongly associated with SES [32]. In the present study, we observed an up to $21.4 \%$ and $19.2 \%$ difference in the prevalence of CS births between women with lower SES compared to the highest SES for nulliparous and multiparous women, respectively, which could be explained by smoking during pregnancy. High risk pregnancies, such as those exhibiting growth restriction, are more likely to result in other complications, such as foetal distress, that require CS birth. However, due to a lack of information on actual CS indications, we could not study that aspect. Furthermore, it might be speculated that a part of SES disparity in giving birth by CS might be explained by differences in delivery training. The results of the present study contradicted those obtained in previous studies, which indicated inequity in both the access to healthcare and healthcare services offered, with a positive social gradient in IVF services [21] and cardiac procedures [19,20] in Finland.

\section{Conclusions}

We conclude that the mode of delivery is an important healthcare policy issue since the constantly rising prevalence of CS births, especially in medium- and high-income countries, does not seem to translate into better maternal and neonatal outcomes [2,29]. In the present study, using the most recent population based data, we detected a decreasing prevalence of planned CS births among singleton pregnancies in Finland with good perinatal outcomes assessed based on several quality indicators [5]. However, we observed a higher prevalence of CS births among women with lower SES compared to the highest SES, which probably reflects the known social gradient in pregnancy complications, and consequently increased need for operative deliveries in women with social deprivation. Overall, the CS policy in Finland shows no inequity in healthcare, which is an important quality indictor in publicly funded services.

\section{Abbreviations}

aOR: Adjusted odds ratio; BMI: Body mass index; Cl: Confidence interval; CS: Caesarean section; FET: Frozen embryo transfers; ICSI: Intracytoplasmic sperm injection; ICD: International classification of diseases; IVF: In vitro fertilization; OR: Odds ratio; SES: Socioeconomic status; THL: National Institute for Health and Welfare; WHO: World Health Organization.

\section{Competing interests}

The authors declare that they have no competing interests.

\section{Authors' contributions}

SR, MG, MRK and SH participated in designing the study. SR managed the dataset and performed statistical analyses. MG, MRK and SH gave advice regarding the statistical analyses. All authors contributed to the interpretation of the results, as well as to the writing and editing of the manuscript. All authors read and approved the final manuscript.

\section{Acknowledgements}

We thank Sees-Editing Ltd for linguistic assistance. The first author (SR) was funded by the Saastamoinen Foundation and Emil Aaltonen Foundation.

\section{Author details}

'Department of Epidemiology, Rollins School of Public Health, Emory University, 1518 Clifton Road NE, Atlanta, GA, USA. ${ }^{2}$ Department of Obstetrics and Gynaecology, Kuopio University Hospital, P.O. Box 100, Kys, Kuopio, FI 70029, Finland. ${ }^{3}$ National Institute for Health and Welfare (THL), P.O. Box 30, Paciuksenkatu 21, Helsinki, FI 00271, Finland. ${ }^{4}$ Nordic School of Public Health, Gothenburg, Sweden. ${ }^{5}$ School of Medicine, University of Eastern Finland, P.O. Box 1627, Kuopio, FI 70211, Finland.

Received: 3 December 2013 Accepted: 26 March 2014

Published: 31 March 2014

\section{References}

1. Gibbons L, Belizán J, Lauer J, Betrán A, Merialdi M, Althabe F: The global numbers and costs of additionally needed and unnecessary caesarean sections performed per year: overuse as a barrier to universal coverage. In World Health Report. 2010. http://www.who.int/healthsystems/topics/ financing/healthreport/30C-sectioncosts.pdf] Accessed 25.11.2013.

2. Althabe F, Sosa C, Belizan JM, Gibbons L, Jacquerioz F, Bergel E: Cesarean section rates and maternal and neonatal mortality in low-, medium-, and high-income countries: an ecological study. Birth 2006, 33(4):270-277.

3. Ronsmans C, Holtz S, Stanton C: Socioeconomic differentials in caesarean rates in developing countries: a retrospective analysis. Lancet 2006, 368(9546):1516-1523.

4. World Health Organization: Appropriate technology for birth. Lancet 1985, 2(8452):436-437.

5. EURO-PERISTAT Project: European Perinatal Health Report. 2008. http://www. europeristat.com] Accessed 25.11.2013.

6. Habiba M, Kaminski M, Da Fre M, Marsal K, Bleker O, Librero J, Grandjean H, Gratia P, Guaschino S, Heyl W, Taylor D, Cuttini M: Caesarean section on 
request: a comparison of obstetricians' attitudes in eight European countries. BJOG 2006, 113(6):647-656.

7. Karlstrom A, Radestad I, Eriksson C, Rubertsson C, Nystedt A, Hildingsson I: Cesarean section without medical reason, 1997 to 2006: a Swedish register study. Birth 2010, 37(1):11-20

8. Penn Z, Ghaem-Maghami S: Indications for caesarean section. Best Pract Res Clin Obstet Gynaecol 2001, 15(1):1-15.

9. Howell S, Johnston T, Macleod SL: Trends and determinants of caesarean sections births in Queensland, 1997-2006. Aust N Z J Obstet Gynaecol 2009, 49(6):606-611.

10. Choudhury AP, Dawson AJ: Trends in indications for caesarean sections over 7 years in a Welsh district general hospital. J Obstet Gynaecol 2009, 29(8):714-717.

11. Liu S, Rusen ID, Joseph KS, Liston R, Kramer MS, Wen SW, Kinch R, Materna Health Study Group of the Canadian Perinatal Surveillance System: Recent trends in caesarean delivery rates and indications for caesarean delivery in Canada. J Obstet Gynaecol Can 2004, 26(8):735-742.

12. Einarsdottir K, Haggar F, Pereira G, Leonard H, de Klerk N, Stanley FJ, Stock S: Role of public and private funding in the rising caesarean section rate: a cohort study. BMJ Open 2013, 3(5). 10.1136/bmjopen-2013-002789.

13. Feng $\mathrm{XL}, \mathrm{Xu} \mathrm{L}$, Guo Y, Ronsmans C: Factors influencing rising caesarean section rates in China between 1988 and 2008. Bull World Health Organ 2012, 90(1):30-39. 39A

14. Lee SI, Khang YH, Yun S, Jo MW: Rising rates, changing relationships: caesarean section and its correlates in South Korea, 1988-2000. BJOG 2005, 112(6):810-819

15. Fairley L, Dundas $\mathrm{R}$, Leyland $\mathrm{AH}$ : The influence of both individual and area based socioeconomic status on temporal trends in Caesarean sections in Scotland 1980-2000. BMC Public Health 2011, 11:330. 2458-11-330.

16. Alves $B$, Sheikh $A$ : Investigating the relationship between affluence and elective caesarean sections. BJOG 2005, 112(7):994-996.

17. Tollanes MC, Thompson JM, Daltveit AK, Irgens LM: Cesarean section and maternal education; secular trends in Norway, 1967-2004. Acta Obstet Gynecol Scand 2007, 86(7):840-848.

18. Lumme S, Sund R, Leyland AH, Keskimäki I: Socioeconomic equity in amenable mortality in Finland 1992-2008. Soc Sci Med 2012, 75(5):905-913.

19. Hetemaa T, Manderbacka K, Reunanen A, Koskinen S, Keskimäki I: Socioeconomic inequities in invasive cardiac procedures among patients with incident angina pectoris or myocardial infarction. Scand J Public Health 2006, 34(2):116-123.

20. Hetemaa T, Keskimäki I, Salomaa V, Mähonen M, Manderbacka K, Koskinen S: Socioeconomic inequities in invasive cardiac procedures after first myocardial infarction in Finland in 1995. I Clin Epidemiol 2004 57(3):301-308.

21. Räisänen $\mathrm{S}$, Randell K, Nielsen HS, Gissler M, Kramer MR, Klemetti R, Heinonen S: Socioeconomic status affects the prevalence, but not the perinatal outcomes, of in vitro fertilization pregnancies. Hum Reprod 2013, 28(11):3118-3125.

22. Klemetti R, Gissler M, Hemminki E: Equity in the use of IVF in Finland in the late 1990s. Scand J Public Health 2004, 32(3):203-209.

23. Klemetti R, Gissler M, Sevon T, Hemminki E: Resource allocation of in vitro fertilization: a nationwide register-based cohort study. BMC Health Serv Res 2007, 7:210.

24. Statistics Finland: Classification of Occupations. 2001. [http://www.tilastokeskus fi/meta/luokitukset/ammatti/001-2001/index.html] Accessed 25.11.2013.

25. Gissler M, Rahkonen O, Arntzen A, Cnattingius S, Andersen AM, Hemminki E: Trends in socioeconomic differences in Finnish perinatal health 19912006. J Epidemiol Community Health 2009, 63(6):420-425.

26. Gissler M, Meriläinen J, Vuori E, Hemminki E: Register based monitoring shows decreasing socioeconomic differences in Finnish perinatal health. J Epidemiol Community Health 2003, 57(6):433-439.

27. Mortensen LH, Lauridsen JT, Diderichsen F, Kaplan GA, Gissler M, Andersen AM: Income-related and educational inequality in small-for-gestational age and preterm birth in Denmark and Finland 1987-2003. Scand Public Health 2010, 38(1):40-45.

28. Bragg F, Cromwell DA, Edozien LC, Gurol-Urganci I, Mahmood TA, Templeton $A$, van der Meulen JH: Variation in rates of caesarean section among English NHS trusts after accounting for maternal and clinical risk: cross sectional study. BMJ 2010, 341:C5065

29. Villar J, Valladares E, Wojdyla D, Zavaleta N, Carroli G, Velazco A, Shah A, Campodonico L, Bataglia V, Faundes A, Langer A, Narvaez A, Donner A,
Romero M, Reynoso S, de Padua KS, Giordano D, Kublickas M, Acosta A, WHO 2005 global survey on maternal and perinatal health research group: Caesarean delivery rates and pregnancy outcomes: the 2005 WHO global survey on maternal and perinatal health in Latin America. Lancet 2006, 367(9525):1819-1829.

30. Räisänen S, Gissler M, Saari J, Kramer M, Heinonen S: Contribution of risk factors to extremely, very and moderately preterm births - registerbased analysis of 1,390,742 singleton births. PLoS One 2013, 8(4):e60660.

31. Räisänen S, Gissler M, Sankilampi U, Saari J, Kramer MR, Heinonen S: Contribution of socioeconomic status to the risk of small for gestational age infants-a population-based study of 1,390,165 singleton live births in Finland. Int J Equity Health 2013, 12:28. 9276-12-28.

32. Blumenshine P, Egerter S, Barclay CJ, Cubbin C, Braveman PA: Socioeconomic disparities in adverse birth outcomes: a systematic review. Am J Prev Med 2010, 39(3):263-272.

doi:10.1186/1471-2393-14-120

Cite this article as: Räisänen et al:: Influence of delivery characteristics and socioeconomic status on giving birth by caesarean section - a cross sectional study during 2000-2010 in Finland. BMC Pregnancy and Childbirth 2014 14:120.

\section{Submit your next manuscript to BioMed Central and take full advantage of:}

- Convenient online submission

- Thorough peer review

- No space constraints or color figure charges

- Immediate publication on acceptance

- Inclusion in PubMed, CAS, Scopus and Google Scholar

- Research which is freely available for redistribution 